\title{
Growth of Ca-Germanide and Ca-Silicide Crystals by Mechanical Alloying*
}

\author{
Yoshifumi Warashina, Yoshifumi Ito, Tamotsu Nakamura, and Hirokazu Tatsuoka ${ }^{\dagger}$ \\ Faculty of Engineering, Shizuoka University, 3-5-1 Johoku, Naka-ku, Hamamatsu 432-8561, Japan \\ Jeff Snyder \\ California Institute of Technology, 1200 California Blvd. Pasadena CA 91125, USA \\ Miyoko Tanaka \\ National Institute for Materials Science, 3-13 Sakura, Tsukuba 305-0003, Japan \\ Takashi Suemasu \\ Institute of Applied Physics, University of Tsukuba, 1-1-1 Tennohdai, Tsukuba, 305-8573, Japan \\ Yoshikazu Anma, Masaru Shimomura, and Yoshihiro Hayakawa \\ Research Institute of Electronics, Shizuoka University, \\ 3-5-1 Johoku, Naka-ku, Hamamatsu 432-8011, Japan \\ (Received 7 October 2008; Accepted 19 January 2009; Published 28 February 2009)
}

\begin{abstract}
Ca-germanide and Ca-silicide crystals were synthesized by mechanical alloying (MA). The resulting powders made from the $\mathrm{Ca}$ and $\mathrm{Si}$ powders contain $\mathrm{Ca}_{2} \mathrm{Si}$ and/or $\mathrm{Ca}_{5} \mathrm{Si}_{3}$ phases with additional cubic phase crystals. The grown phases, namely $\mathrm{Ca}_{2} \mathrm{Si}$ and $\mathrm{Ca}_{5} \mathrm{Si}_{3}$, can be controlled by the $\mathrm{Ca} / \mathrm{Si}$ ratio and the $\mathrm{Si}$ powder size. For the powders synthesized using the $\mathrm{Ca}$ and Ge powders, the cubic crystalline phase was synthesized. It was found that the powders synthesized from the $\mathrm{Ca}$ and Ge powders are covered by an amorphous layer that contains oxidized carbons. The Ca-based bulk tablets pressed from the powders show a $p$-type semiconducting behavior, though the powder surface is heavily oxidized, which might affect the transport property of the bulk.
\end{abstract}

[DOI: 10.1380/ejssnt.2009.129]

Keywords: Transmission high-energy electron diffraction; Nano-particles, quantum dots, and supra-molecules; Powders; Silicides; Alloys

\section{INTRODUCTION}

Recently, semiconducting silicides, which consist of non- toxic and abundant materials, have attracted much attention for their potential to create new classes of environmentally conscious electronics [1]. Alkaline-earth metal (AEM) silicides are categorized in this materials group. The growth of AEM silicides and their applications to solar cell and thermoelectric materials have been investigated [2]. The electronic properties of the AEM silicides have been comprehensively investigated $[3,4]$. Concerning the Ca-based silicides, the $\mathrm{Ca}_{2} \mathrm{Si}$ layers and bulk crystals were successfully grown using $\mathrm{Mg}_{2} \mathrm{Si} / \mathrm{Si}$ and $\mathrm{Mg}_{2} \mathrm{Si}$ substrates, respectively [5-7]. Moreover, the $\mathrm{Ca}_{5} \mathrm{Si}_{3}$ powders were obtained by the heat treatment of Si powders under Ca vapor [8]. It is important to systemically understand the science and technology of this new silicide family for further developing the sustainable optoelectronic technology using silicides and related materials. The growth of these Ca-based silicides has been carried out by a reactive deposition technique in a vacuum. On the other hand, materials synthesized by the mechanical alloying (MA) technique may be crystalline, quasi-crystalline or amorphous in nature. It is also possible to synthesize metastable phases with an unknown structure by MA [9]. It is expected that the MA method combined with the

\footnotetext{
* This paper was presented at International Symposium on Surface Science and Nanotechnology (ISSS-5), Waseda University, Japan, 9-13 November, 2008.

†Corresponding author: tehtats@ipc.shizuoka.ac.jp
}

recent silicide technology would provide further development of new semiconducting silicide technologies.

In this study, powders containing Ca-based compounds, such as Ca-germanides and Ca-silicides, were synthesized by MA and their structural properties were investigated as the first step in the development. In addition, the electric property of the powders was also characterized.

\section{EXPERIMENTAL}

Ca-based containing Si or Ge powders were synthesized by MA. As the starting materials, 325 mesh Si powder (36 micrometer APS, 99.999\%), fine Si powder (0.07-0.10 micrometer APS, 98\%) or Ge powder (-100 mesh, 99.999\%), and Ca granules (-16 mesh, 99.5\%) were used. Ca and Si (or $\mathrm{Ge}$ ) powders were weighed in the molar ratio of $\mathrm{Ca}: \mathrm{Si}$ ( or $\mathrm{Ge})=2: 1$ to $7: 3$. The powders and two $1 / 2$ inch or four $1 / 4$ inch steel milling balls were placed in a steel vial under an argon atmosphere, then the vial was sealed by an O-ring. The milling was carried out in a SPEX 8000 vibratory mill.

The structural properties of the resulting powders were characterized by X-ray diffraction (XRD) measurements, scanning electron microscopy (SEM) and transmission electron microscopy (TEM). In addition, the compositional analysis was completed using energy dispersive $\mathrm{X}$ ray spectroscopy (EDS).

In addition, the surface condition of the powders, was characterized by X-ray photoelectron spectroscopy (XPS) using a VG, ESCA-LAB Mk II with a nonmonochromatized $\mathrm{Al} \mathrm{K}_{\alpha}$ source $(h \nu=1486.6 \mathrm{eV})$. The 


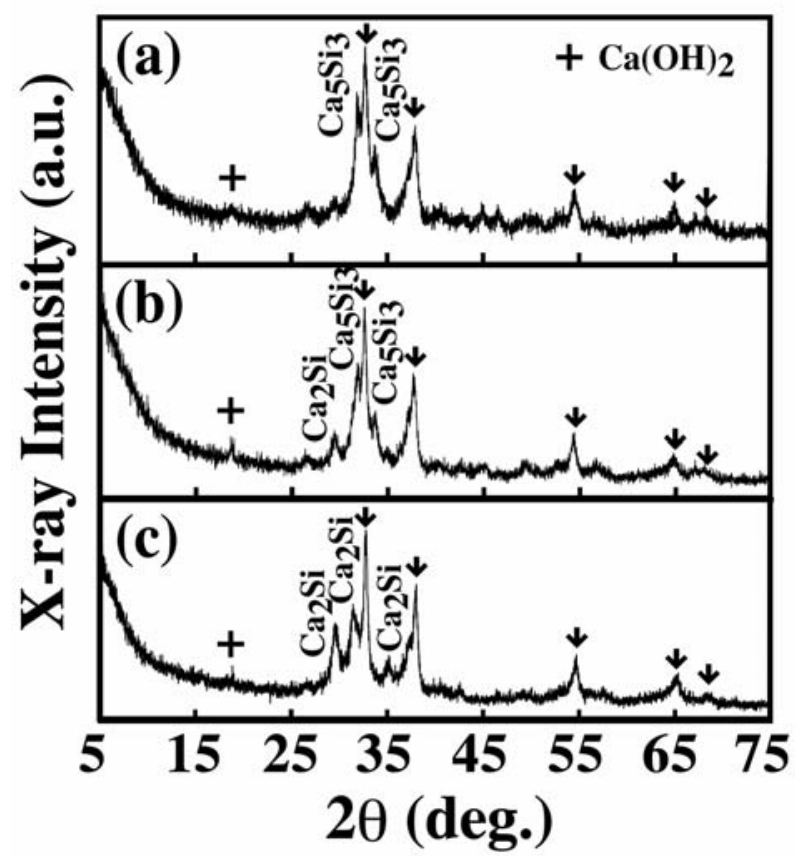

FIG. 1: XRD spectra of resultant Ca-silicide powder synthesized using (a) the 325 mesh $\mathrm{Si}$ powder with $\mathrm{Ca}: \mathrm{Si}=2: 1$ for 136 h, (b) the 325 mesh Si powder with $\mathrm{Ca}: \mathrm{Si}=7: 3$ for $90 \mathrm{~h}$, and (c) the fine $\mathrm{Si}$ powder with $\mathrm{Ca}: \mathrm{Si}=7: 3$ for $57 \mathrm{~h}$. Two 1/2 inch steel milling balls were used for the milling in these cases.

powders were stuck to sample stages by carbon adhesive tape.

For the electric measurements, the powders were pressed at $400^{\circ} \mathrm{C}$ for $2 \mathrm{~h}$, or at room temperature to make tablets with about a $1 \mathrm{~mm}$ height and $5 \mathrm{~mm}$ diameter. The resistivity was measured by the conventional fourprobe method, and the conductivity type was determined by the conventional thermo-probe technique.

\section{RESULTS AND DISCUSSION}

Figure 1(a) shows the XRD spectrum of the resulting powders synthesized using the 325 mesh Si powder with $\mathrm{Ca}: \mathrm{Si}=2: 1$ for $136 \mathrm{~h}$. A series of diffraction peaks due to the $\mathrm{Ca}_{5} \mathrm{Si}_{3}$ phase is observed with additional diffraction patterns. Figure 1(b) shows the XRD spectrum of the resulting powders synthesized using the 325 mesh Si powder with $\mathrm{Ca}: \mathrm{Si}=7: 3$ for $90 \mathrm{~h}$. Overlapped diffraction patterns due to $\mathrm{Ca}_{5} \mathrm{Si}_{3}$ and $\mathrm{Ca}_{2} \mathrm{Si}$ are observed with the additional diffraction patterns the same as those observed in Fig. 1(a). On the other hand, Fig. 1(c) shows the XRD spectrum of the resulting powders synthesized using the fine Si powder with $\mathrm{Ca}: \mathrm{Si}=7: 3$ for $57 \mathrm{~h}$. A series of diffraction peaks due to the $\mathrm{Ca}_{2} \mathrm{Si}$ phase is observed with the additional diffraction patterns the same as those observed in Fig. 1(a). For these cases, two $1 / 2$ inch steel milling balls were used for the milling. It is considered that the $\mathrm{Ca}$ rich condition and smaller particle size of the Si powder enhances the formation of the $\mathrm{Ca}_{2} \mathrm{Si}$ phase due to the increased $\mathrm{Ca} / \mathrm{Si}$ flux ratio at the reaction front between the $\mathrm{Si}$ and $\mathrm{Ca}$ powders. The small diffraction peaks around $18.5^{\circ}$ are due to $\mathrm{Ca}(\mathrm{OH})_{2}$, which is formed by the pres-

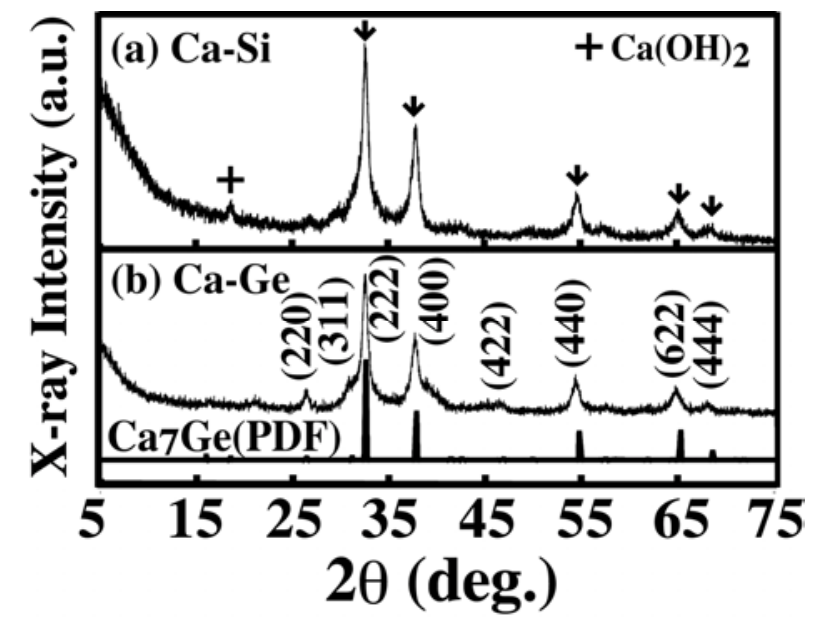

FIG. 2: (a) XRD spectrum of the powders synthesized from the $\mathrm{Ca}$ and $\mathrm{Si}$ powders with four $1 / 4$ inch steel milling balls for $50 \mathrm{~h}$. (b) XRD spectrum of the powders synthesized from the $\mathrm{Ca}$ and Ge powders using two $1 / 2$ inch steel milling balls for $123 \mathrm{~h}$. The simulated XRD pattern of $\mathrm{Ca}_{7} \mathrm{Ge}$ is also shown in (b).

ence of the residual air in the vial.

It is noted that a series of additional diffraction peaks are observed in Figs. 1(a), (b) and (c), and the pattern is typical for a cubic crystalline phase. Figure 2(a) shows the XRD spectrum of the powders synthesized using the fine $\mathrm{Si}$ powder with $\mathrm{Ca}: \mathrm{Si}=7: 3$ for $57 \mathrm{~h}$ with four $1 / 4$ inch steel milling balls for $50 \mathrm{~h}$. The diffraction peaks due to $\mathrm{Ca}_{5} \mathrm{Si}_{3}$ and $\mathrm{Ca}_{2} \mathrm{Si}$ disappear, and a series of additional peaks becomes dominant. Diffraction peaks are also observed in the XRD spectrum of powders synthesized from Ca:Ge $=2: 1$ using two $1 / 2$ inch steel milling balls for 123 $\mathrm{h}$, as shown in Fig. 2(b). For Ca-germanide in the $\mathrm{Ca}-\mathrm{Ge}$ system, the simulated XRD pattern of the $\mathrm{Ca}_{7} \mathrm{Ge}$ crystal well agrees with that of the observed XRD spectrum [10].

However, the EDS measurements of the powders shown in Fig. 2 show that the average chemical composition of the powders are roughly $\mathrm{Ca}: \mathrm{Si} \simeq 2: 1$ for the powders synthesized from $\mathrm{Ca}-\mathrm{Si}, \mathrm{Ca}: \mathrm{Ge} \simeq 3: 1$ for $\mathrm{Ca}-\mathrm{Ge}$.

Figures 3(a) and (b) show the TEM images and corresponding diffraction patterns of the powders synthesized from the $\mathrm{Ca}$ and $\mathrm{Si}$ powders, and the $\mathrm{Ca}$ and Ge powders shown in Figs. 2(a) and (b). The lattice spacing observed by the diffraction pattern agrees with those of the XRD spectra shown in Figs. 2(a) and (b). The diffraction patterns in Fig. 3(b) are labeled using the lattice spacings of the $\mathrm{Ca}_{7} \mathrm{Ge}$ type crystal. Figure 4 shows an HRTEM image of one of the powders synthesized from the $\mathrm{Ca}$ and $\mathrm{Ge}$ powders shown in Fig. 3(b). The lattice spacings shown in the figure well agree with those shown in the diffraction pattern in Fig. 3(b). The powders consist of domains with a size of about $5 \mathrm{~nm}$, and the surface of the powder is covered with a thin $(\sim 2 \mathrm{~nm})$ amorphous layer.

Figure 5 shows the XPS spectrum of the powders synthesized from the $\mathrm{Ca}$ and Ge powders. It was found that strong peaks due to $\mathrm{C}$ are observed as well as peaks due to $\mathrm{Ca}$ and $\mathrm{O}$. On the other hand, smaller peaks due to $\mathrm{Si}$ are obtained. It should be noted that three peaks are observed for the C $1 s$ related signals. Peak A around 287 

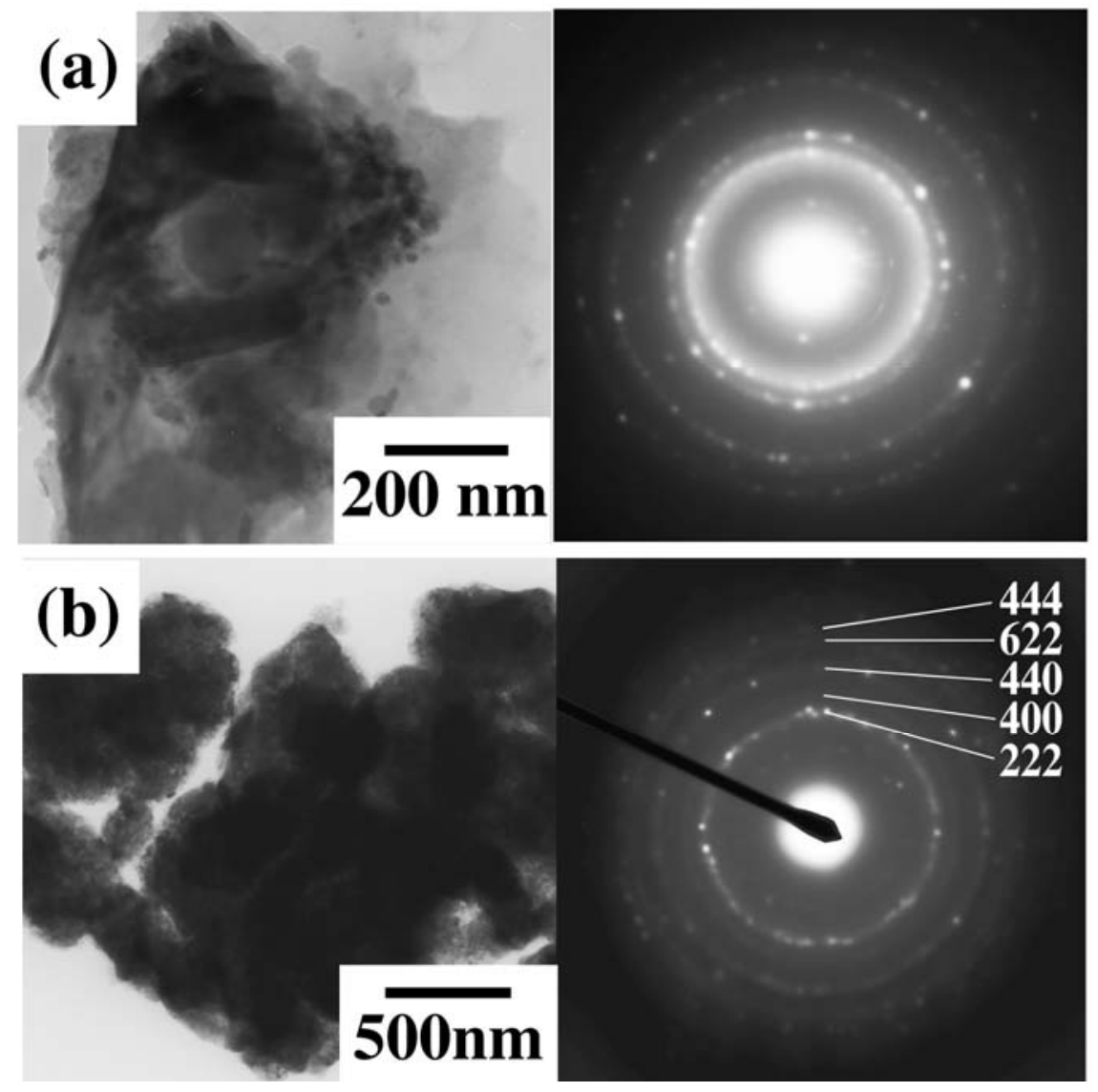

FIG. 3: TEM images and corresponding diffraction patterns of the powders synthesized from (a) Ca and Si powders, and (b) $\mathrm{Ca}$ and Ge powders shown in Figs. 2(a) and (b), respectively.

TABLE I: Preparation conditions of tablets made from the powders.

\begin{tabular}{llll}
\hline \hline Tablet & Powder & Temperature / Duration & Pressure \\
\hline (a) & $\mathrm{Ca}_{2} \mathrm{Si}+$ cubic phase in Fig. & $400^{\circ} \mathrm{C} / 1 \mathrm{~h}$ & $87 \mathrm{MPa}$ \\
(b) & Ca-Si cubic phase in Fig. & $\mathrm{RT} / 15 \mathrm{~min}$ & $500 \mathrm{MPa}$ \\
(c) & Ca) $(\mathrm{a})$ & $\mathrm{RT} / 15 \mathrm{~min}$ Fig. 2(b) & $10 \mathrm{MPa}$ \\
\hline
\end{tabular}

$\mathrm{eV}$ is correspond to carbons included in a carbon adhesive tape or hydrocarbons attached directly on the tape, which is detected through interspace of the powders. Peak $\mathrm{B}$ and peak $\mathrm{C}$ are non-oxidized and oxidized carbons of the powder samples. They are shifted about $7 \mathrm{eV}$ to a higher binding energy caused by electric charge-up of the samples. Peak B is due to hydrocarbons, which is usually observed for a contaminated surface. The peak $\mathrm{C}$ is energetically shifted around $5 \mathrm{eV}$ from the peak $\mathrm{B}$. The significant shift indicates carbons of the peak $\mathrm{C}$ is heavily oxidized. These XPS results were taken for the amorphous layer on the powder surface as shown in Fig. 4. It is considered that the surface of the powders are heavily oxidized by the formation of oxidized carbons, for example, $\mathrm{CaCO}_{3}$, etc.

Figure 6 shows the temperature dependence of the conductivity of the tablets made from the powders. The tablets were made under the conditions shown in Table
I. The electrical measurements of the tablets show their $p$-type semiconducting behavior as shown in the figure. The existence of the hydroxide and oxides on the powder surface significantly affect the transport phenomena of the Ca compound bulk crystals.

The compound, which causes the additional diffraction peaks that appear in observed XRD spectra, has not been clarified at this moment. The crystalline structure of the cubic $\mathrm{Ca}_{2} \mathrm{Si}$ has been previously reported [11], and the Powder diffraction Pattern File (PDF) well agrees with the experimental results. However, because of the uncertainty of the data, the phase cannot be identified as cubic $\mathrm{Ca}_{2} \mathrm{Si}$ (JCPDS Card No. 02-0881 and 03-0798). According to the PDF, the diffraction angles of the peaks due to $\mathrm{CaO}$ roughly agree with those of the experimental results, but their intensity distribution does not agree with the experimental results. The band structure of the cubic $\mathrm{Ca}_{2} \mathrm{Si}$ (anti- $\mathrm{CaF}_{2}$ crystalline structure) was calculated and the 


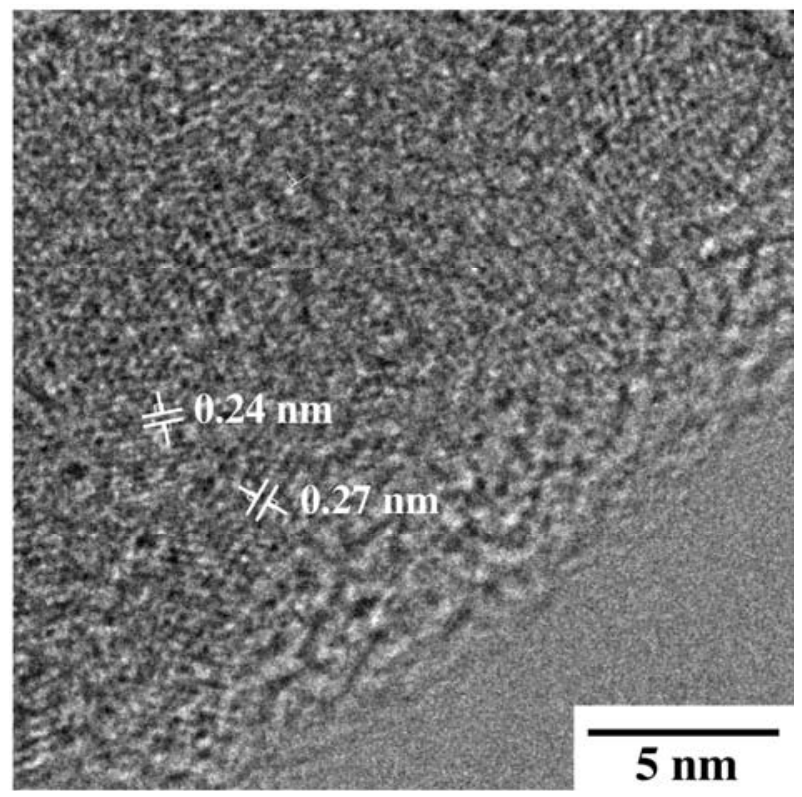

FIG. 4: HRTEM image of one of the powders synthesized from the $\mathrm{Ca}$ and Ge powders shown in Fig. 3(b).

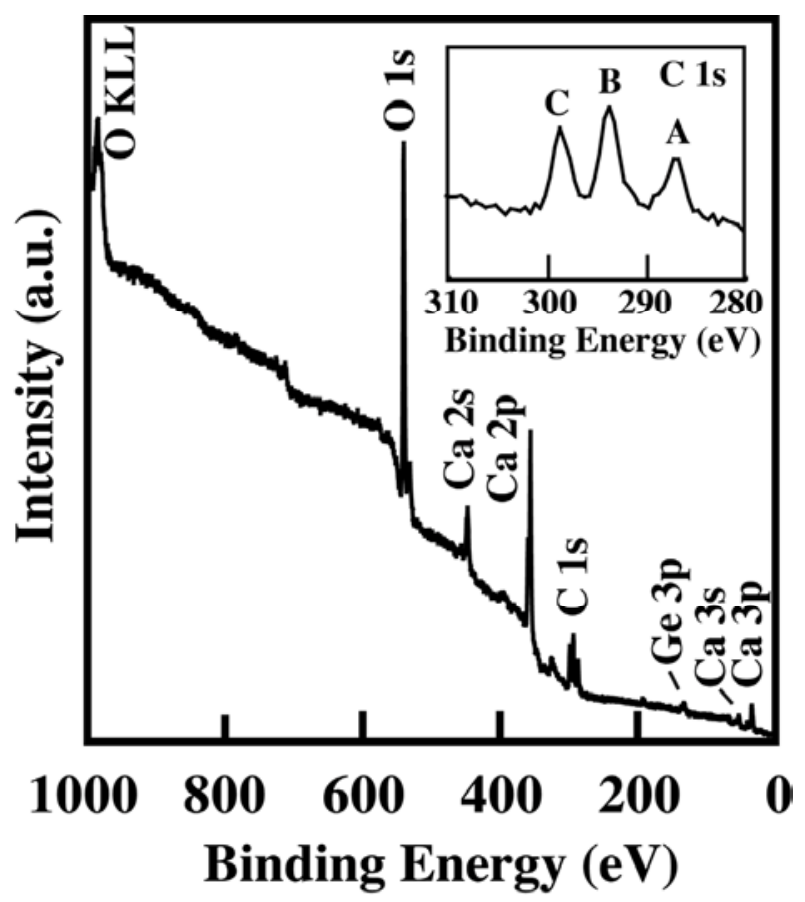

FIG. 5: XPS spectrum of the powders synthesized from the $\mathrm{Ca}$ and Ge powders. An enlarged spectra related to $\mathrm{C} 1 \mathrm{~S}$ is shown in the inset.

optimized lattice constant is $7.148 \AA$ [4], which does not agree with the observed experimental result.

It is possible that the crystalline phase, which has a cubic crystalline structure, such as the $\mathrm{Ca}_{7} \mathrm{Ge}$ type, appear in the powders synthesized from the $\mathrm{Ca}$ and Ge powders, because of the stoichiometric distribution in the powders caused by the incomplete alloying. It is also considered as one of the possibilities that the cubic phase Ca-related compounds, such as a crystalline structure similar to the

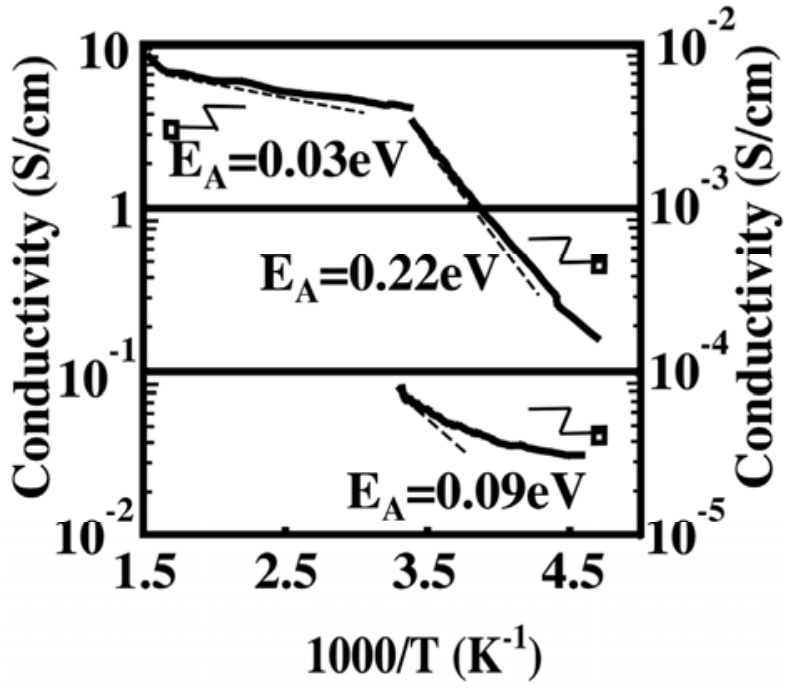

FIG. 6: Temperature dependence of the conductivity of the tablets made from the powders under the preparation conditions shown in Table I. The density of these tablets is about $80 \%$.

$\mathrm{Ca}_{7} \mathrm{Ge}$ type, is formed for the powder synthesized from the $\mathrm{Ca}$ and $\mathrm{Si}$ powders.

The development of reactive deposition techniques has allowed us to grow new novel silicides, such as $\mathrm{Ca}_{2} \mathrm{Si}$ and $\mathrm{Sr}_{2} \mathrm{Si}[5-8,12]$. In addition, a vacuum-free growth technique for the $\beta$-FeSi $i_{2}$ layers or bulk preparations has been developed on the basis of the reactive deposition techniques [13]. The use of $\mathrm{MnCl}_{2}$ as a source material was also examined in order to grow $\mathrm{MnSi}_{1.7}$ layers [14]. It has also been pointed out that the selective growth of a particular phase by the solid-phase reaction is mainly triggered by the interfacial composition, and is governed by the diffusion of the flux to the interface [15]. Moreover, the silicide growth strongly depends on the boundary conditions and not simply on the free energy of formation [16]. On the other hand, during the MA process, the powders are repeatedly flattened, cold welded, fractured and rewelded. The processes of cold welding and fracturing, as well as their kinetics, mostly depend on the deformation characteristics of the powders, and the new phase formation is determined by short-range interdiffusion of the constituents [9]. The interdiffusion process enhanced by the deformation would modify the reaction path through the silicide compounds [6]. It is expected that silicide materials or nano-scaled composites can be synthesized which cannot be usually synthesized by the conventional interdiffuion technique or reactive deposition technique. A detailed study of the structural analysis of the powders is now in progress. Further investigations will be required to understand and develop the new silicide family science and technology.

\section{CONCLUSIONS}

Ca-germanide and Ca-silicide powders were synthesized by MA. The $\mathrm{Ca}_{5} \mathrm{Si}_{3}$ powder was synthesized using the $\mathrm{Ca}: \mathrm{Si}=2: 1$ powder starting materials. With the increas- 
ing $\mathrm{Ca} / \mathrm{Si}$ ratio, the $\mathrm{Ca}_{2} \mathrm{Si}$ phase was formed. In addition, the use of the fine $\mathrm{Si}$ powder enhanced the formation of the $\mathrm{Ca}_{2} \mathrm{Si}$. Moreover, the $\mathrm{Ca}_{2} \mathrm{Si}$ and $\mathrm{Ca}_{5} \mathrm{Si}_{3}$ powders were obtained with additional cubic phase crystals. For the powders synthesized from the $\mathrm{Ca}$ and Ge powders, a cubic crystalline phase was also formed, and the observed lattice spacings of the crystals well agreed with those of the $\mathrm{Ca}_{7} \mathrm{Ge}$ type cubic crystalline structure. The Ca-based compound bulk tablets pressed from the powder showed a $p$-type semiconducting behavior, though the powder surface might be heavily oxidized, which might affect the transport property of the bulk. They can be considered new materials in the semiconducting silicide family, and their further development is expected.

\section{Acknowledgments}

A part of this work was supported by the "Nanotechnology Support Project" and a Grant-in-Aid for Scientific Research from the Ministry of Education, Culture, Sports, Science and Technology (MEXT), Japan.
[1] Y. Makita, in: Mc Connel (Ed.), The First NREL Conference on Future Generation Photovoltaic Technologies (AIP, New York, 1997), p. 3.

[2] Y. Maeda, K. P. Homewood, T. Sadoh, Y. Terai, K. Yamaguchi, and K. Akiyama (Eds.), Proceedings of AsiaPacific Conference on Semiconducting Silicides Science and Technology Towards Sustainable Optoelectronics, Kyoto, Japan, 29-31 July 2006; Thin Solid Films 515, (2007).

[3] Y. Imai, A. Watanabe, and M. Mukaida, J. Alloys Comp. 358, 257 (2003).

[4] D. B. Migas, L. Miglio, V. L. Shaposhnikov, and V. E. Borisenko, Phys. Rev. B 67, 205203 (2003).

[5] H. Matsui, M. Kuramoto, T. Ono, H. Nose, H. Tatsuoka, and H. Kuwabara, J. Cryst. Growth 237/239, 2121 (2002).

[6] T. Hosono, M. Kuramoto, Y. Matsuzawa, Y. Momose, Y. Maeda, T. Matsuyama, H. Tatsuoka, Y. Fukuda, S. Hashimoto, and H. Kuwabara, Appl. Surf. Sci. 216, 620 (2003).

[7] N. Takagi, Y. Sato, T. Matsuyama, H. Tatsuoka, M. Tanaka, F. Chu, and H. Kuwabara, Appl. Surf. Sci. 244, 330 (2005).
[8] T. Inaba, A. Kato, K. Miura, M. Akasaka, T. Iida, Y. Momose, and H. Tatsuoka, Thin Solid Films 515, 8226 (2007).

[9] C. Suryanarayana, Mechanical Alloying and Milling (Marcel Dekker, New York, 1997).

[10] Von O. Helleis, H. Kandler, E.Leicht, W. Quiring, and E. Wölfel, Z. Anorg. Allg. Chem. 320, 86 (1963).

[11] V. Louse and H. H. Franck, Z. Anorg. Chem. 242, 117 (1939).

[12] K. Miura, T. Ohishi, T. Inaba, Y. Mizuyoshi, N. Takagi, T. Matsuyama, Y. Momose, T. Koyama, Y. Hayakawa, and H. Tatsuoka, Thin Solid Films 508, 74 (2006) .

[13] T. Ohishi, Y. Mizuyoshi, T. Matsuyama, H. Tatsuoka, and H. Kuwabara, Thin Solid Films 461, 63 (2004).

[14] H. Junhua, T. Kurokawa, T. Suemasu, S. Takahara, M. Itakura, and H. Tatsuoka, Phys. Stat. Sol. (a) 206, 233 (2009).

[15] G. Majni, C. Nobili, G. Ottaviani, M. Costaato, and E. Galli, J. Appl. Phys. 52, 4047 (1981).

[16] K. N. Tu, G. Ottaviani, R. D. Thompson and J. W. Mayer, J. Appl. Phys. 53, 4406 (1982). 